\title{
Higher-Than-Conventional Subcutaneous Regular Insulin Doses in Diabetic Ketoacidosis in Children and Adolescents
}

\author{
Özlem Bağ ${ }^{1}$, Selma Tunç ${ }^{2}$, Özlem Nalbantoğlu ${ }^{2}$, Çiğdem Ecevit ${ }^{1}$, Aysel Öztürk ${ }^{1}$, Behzat Özkan ${ }^{2}, K^{\prime}$ Korcan Demir ${ }^{3}$ \\ ${ }^{1}$ Dr. Behçet Uz Children's Hospital, Clinic of Pediatrics, izmir, Turkey \\ ${ }^{2}$ Dr. Behçet Uz Children's Hospital, Clinic of Pediatric Endocrinology, Izmir, Turkey \\ ${ }^{3}$ Dokuz Eylül University Faculty of Medicine, Department of Pediatrics, Division of Pediatric Endocrinology, İmir, Turkey
}

\section{What is already known on this topic?}

Although dosages of $0.5 \mathrm{U} / \mathrm{kg} /$ day to $2 \mathrm{U} / \mathrm{kg} /$ day have been used as initial doses in various diabetes centers, little is known about their effect on glycemic control in new-onset type 1 diabetes mellitus (T1DM).

\section{What this study adds?}

An initial dose of 1.4-1.5 U/kg/day regular insulin may safely be used after resolution of diabetic ketoacidosis in children with new-onset T1DM without an increased risk of hypoglycemia.

\section{Abstract}

Objective: To evaluate the effect of initial insulin dosage on glycemic control in the first 48 hours of subcutaneous regular insulin therapy after resolution of diabetic ketoacidosis (DKA).

Methods: Records of patients with DKA hospitalized in the past 3 years [ $n=76$, median age $=10.0$ (6.0-12.0) years, Male/Female: 44/32] were reviewed. The patients were designated into two groups according to distribution of starting doses of subcutaneous insulin. Group $1(n=28)$ received a median dose of $1.45 \mathrm{U} / \mathrm{kg} /$ day $(1.41-1.5)$ and group $2(n=48)$ a median dose of $0.96 \mathrm{U} / \mathrm{kg} / \mathrm{day}(0.89-1)$. Clinical and laboratory data were analyzed.

Results: Median, minimum, and maximum blood glucose levels of Group 1 in the first 48 hours of treatment were significantly lower than that of Group 2 [213 (171-242) vs. 255 (222-316), $p=<0.001$; 102 (85-151) vs. 129 (105-199), p=0.004; and 335 (290-365) vs. 375 (341 438), $\mathrm{p}=0.001$, respectively]. The number of patients who experienced hypoglycemia ( $<70 \mathrm{mg} / \mathrm{dL}) \mathrm{were}$ similar [Group 1 , $5(17.9 \%)$ vs. Group 2, $4(8.3 \%), p=0.276$ ] and none had severe hypoglycemia. In Group 1, the ratio of blood glucose levels within the target range $(100-200 \mathrm{mg} / \mathrm{dL})$ were higher $(37.5 \%$ vs. $12.5 \%)$ and the number of results $>200 \mathrm{mg} / \mathrm{dL}$ were lower $(50 \%$ vs. $81.3 \%)$ compared to Group 2 ( $\mathrm{p}=0.001$ and $\mathrm{p}<0.001$, respectively).

Conclusion: After resolution of DKA, a higher initial dose of 1.4-1.5 U/kg/day regular insulin is associated with better glycemic control in children and adolescents without an increase in risk of hypoglycemia.

Keywords: Type 1 diabetes mellitus, regular insulin, initial doses, children, adolescent

\section{Introduction}

Diabetic ketoacidosis (DKA) occurs in 20-40\% of children and adolescents with new-onset type 1 diabetes mellitus (T1DM) and after DKA resolves, the therapy is switched to any insulin regimen that aims to control blood glucose (BG) levels. It is known that the required initial daily insulin dose may vary according to many factors including age, body weight, stage of puberty, duration and phase of diabetes (1). The optimal insulin dose for the patient can only be determined empirically (2). An excellent initial insulin dose estimate is one that provides tight BG control and minimizes the risk of hypoglycemia.
Address for Correspondence: Özlem Bağ MD,

Dr. Behçet Uz Children's Hospital, Clinic of Pediatrics, İzmir, Turkey

Phone: +902324646167 E-mail: bagozlem78@yahoo.com

This study was presented in "The 55 $5^{\text {th }}$ Annual European Society for Pediatric Endocrinology" 10-12 September 2016, Paris, France

${ }^{-}$Copyright 2017 by Turkish Pediatric Endocrinology and Diabetes Society

The Journal of Clinical Research in Pediatric Endocrinology published by Galenos Publishing House.
Conflict of interest: None declared Received: 08.11.2016 Accepted: 25.12 .2016 
Regular insulin is a soluble crystalline zinc insulin, an essential component of most daily replacement regimens (3). Due to its chemical structure, it has a wide peak and a long tail for bolus insulin, and thus cannot mimic the activity of the $\beta$ cell but is available to initiate treatment after resolution of DKA and serves to determine the daily insulin dose before basal-bolus insulin regimen. Although guidelines recommend $0.5-1.0 \mathrm{U} / \mathrm{kg} /$ day of subcutaneous insulin following resolution of DKA, up to 2 units $/ \mathrm{kg} / \mathrm{d}$ are used in various centers, depending on the preference and experience of the particular diabetes team.

It has previously been reported that intensive insulin therapy would improve endogenous insulin secretion, consequently leading to better metabolic control (4). Thus, one of the aims of therapy following DKA is to control BG levels as early as possible. Higher initial insulin doses could rapidly decrease BG level, but their effect on BG fluctuations have not been extensively investigated (5). This present study aimed to evaluate the effect of the initial insulin dose on glycemic control in the first 48 hours of DKA treatment in children and adolescents with new-onset T1DM and also to compare BG fluctuations with higher and conventional doses of subcutaneous regular insulin therapy.

\section{Methods}

The study was conducted in one of the major tertiary hospitals in the region. Hospital records of patients who presented in the last 3 years were reviewed for the study. Diagnosis of T1DM and DKA were made according to the 2014 International Society for Pediatric and Adolescent Diabetes (ISPAD) Clinical Practice Consensus Guidelines for Diabetes in Childhood and Adolescence (6). Newborns, patients who had been treated with any insulin or antihyperglycemic drugs before admission, patients having additional endocrine (hypo-hyperthyroidism, hypo-hypercortisolism, etc.) or non-endocrine diseases (any infectious or inflammatory disease), and those with inadequate hospital records were excluded. Finally, 76 children and adolescents [median age $=10.0$ (6.0-12.0) years, Male/Female: 44/32] who presented with DKA due to new-onset T1DM were enrolled as the study group. Age, gender, stage of puberty (patients were noted as pubertal if they had at least Tanner 2 breast development or $\geq 4 \mathrm{~mL}$ testicular volume), body weight and height, glycosylated hemoglobin (HbA1c) levels, BG levels on admission and at the start of regular subcutaneous insulin, insulin dose administered for DKA, and initial dose of regular subcutaneous insulin were recorded. As shown in Figure 1, the patients were designated into two groups according to distribution of starting doses of subcutaneous insulin. Group 1 consisted of patients who received $\geq 1.25 \mathrm{U} /$ $\mathrm{kg} /$ day $[\mathrm{n}=28$, median dose $=1.45 \mathrm{U} / \mathrm{kg} /$ day $(1.41-1.5)]$ and Group 2 consisted of those who were treated with $<1.25 \mathrm{U} /$ $\mathrm{kg} /$ day $[\mathrm{n}=48$, median dose $=0.96 \mathrm{U} / \mathrm{kg} /$ day $(0.89-1)]$.

Clinical and laboratory data were collected and analyzed after Behçet Uz Children's Hospital Ethics Committee's approval, in concordance with the principles of Declaration of Helsinki (7).

\section{Treatment Protocol}

After resolution of DKA, all patients with new-onset T1DM were started on regular insulin (Humulin R, Lilly, USA) every 6 hours to determine the daily insulin requirement before transition to basal-bolus regimen. As the tissue half-life of insulin is longer than that of intravenous insulin, the first dose of subcutaneous basal insulin was given 30 min before the cessation of intravenous insulin infusion. Premeal BG measurement was performed before each insulin injection 30 minutes before the meals and the insulin dose was determined according to the BG levels: $100-200 \mathrm{mg} / \mathrm{dL}$, same as the previous dose; $>200 \mathrm{mg} / \mathrm{dL}, 110 \%$ of the previous dose; $<100 \mathrm{mg} / \mathrm{dL}, 90 \%$ of the previous dose (2). The insulin dose was also adjusted according to the consumed amount of the meals. The decision to switch to basal-bolus regimen was made when no significant change was needed in regular insulin doses, generally after 3-4 days. BG levels were measured more frequently in patients who suffered from any symptom of hypo- or hyperglycemia. During hospitalization, the meals of the patients were prepared by dietitians according to the ISPAD Clinical Practice Consensus Guidelines 2014 on nutritional management in children and adolescents with diabetes. The diets contained carbohydrates providing approximately $50-55 \%$, fat up to $30-35 \%$, and protein $10-15 \%$ of daily energy requirements (8). Four meals and three snacks were given a day and no additional food was consumed unless hypoglycemic events occurred.

\section{Study Variables}

Descriptive characteristics of the patients, treatment information, and every BG measurement during the first 48 hours of subcutaneous regular insulin treatment were recorded. Glycemic variability indices [standard deviation $(\mathrm{SD})$, coefficient of variation (CV), maximum $\mathrm{BG}$, minimum $B G$, difference between maximum and minimum $B G$, rate of BG change (the amount of change between consecutive measurements, $\mathrm{mg} / \mathrm{dL} / \mathrm{min})]$ were calculated. All BG measurements were performed by the same capillary BG monitoring system (Astracheck Plus ${ }^{8}$, Medisign MM 600, Empecs, Beijing, China), an electrochemical glucometer using the modified glucose oxidase method, calibrated monthly by electronical calibrators. 


\section{Statistical Analysis}

The data were statistically analyzed using computer software SPSS 15.0 (Chicago, IL, USA). Mann-Whitney U-test and chisquare test were used to compare numerical and categorical variables, respectively, between groups. Univariate correlation analysis was performed between insulin starting dose and median glucose levels during 48 hours. General linear model with repeated measures was applied to assess the differences between the groups regarding the trajectory of glucose levels. Wilcoxon two-related samples test was employed to compare insulin doses at the start and at the $48^{\text {th }}$ hour of treatment among groups. A p-value of $<0.05$ was chosen to represent statistical significance. Data were presented as median (25p-75p) or $n(\%)$.

\section{Results}

The study consisted of 76 children and adolescents [median age $=10.0$ (6.0-12.0); age range, $1.5-16.0$ years; M/F: 44/32] with new onset T1DM admitting with DKA. Thirty six patients $(47.4 \%)$ were pubertal. The median BG level on admission was $466 \mathrm{mg} / \mathrm{dL}$ (383-574) while the median BG level at the start of insulin was $158 \mathrm{mg} / \mathrm{dL}$ (123-198). Baseline characteristics of the study group are presented in Table 1.

Group 1 and Group 2 were comparable regarding age, gender, pubertal status, HbA1c, and BG levels both on admission and at the start of subcutaneous insulin treatment. Table 2 presents the descriptive data of the groups.

Both of the groups had similar numbers of BG measurements [Group 1, 8 (8-8) vs. Group 2, 8 (8-8)], p=0.250). Median BG levels of Group 1 in the first 48 hours were significantly

Table 2. Descriptive data of patients among the two groups

\begin{tabular}{|c|c|c|c|}
\hline & Group $1(n=28)$ & Group $2(n=48)$ & $\mathrm{p}$ \\
\hline Age (years) & $10.5(5.63-13.6)$ & $9(6-11.9)$ & 0.205 \\
\hline Male & $15(53.6 \%)$ & $29(60.4 \%)$ & 0.560 \\
\hline Pubertal patients & $15(53.6 \%)$ & $21(44 \%)$ & 0.479 \\
\hline Blood glucose on admission (mg/dL) & $465(366-577)$ & $466(394-573)$ & 0.635 \\
\hline $\mathrm{pH}$ & $7.18(7.06-7.24)$ & $7.16(7.03-7.24)$ & 0.987 \\
\hline Bicarbonate (mmol/L) & $9.6(7.3-11.7)$ & $8.5(5.5-13)$ & 0.983 \\
\hline $\operatorname{HbA1c}(\%)$ & $12.8(11.2-14.6)$ & $12.5(10.6-13.8)$ & 0.598 \\
\hline Dose of insulin infusion (U/h) & $0.1(0.1-0.1)$ & $0.1(0.1-0.1)$ & 0.999 \\
\hline Blood glucose at the start of subcutaneous insulin $(\mathrm{mg} / \mathrm{dL})$ & $159(124-194)$ & $157(123-200)$ & 0.718 \\
\hline Starting insulin dose (U/kg/day) & $1.45(1.41-1.5)$ & $0.96(0.89-1)$ & $<0.001$ \\
\hline Insulin dose on $1^{\text {st }}$ day (U/kg/day) & $1.5(1.41-1.56)$ & $0.99(0.93-1.03)$ & $<0.001$ \\
\hline
\end{tabular}

lower than those of Group 2 [213 (171-242) vs. 255 (222$316), p=<0.001]$. Figure 2 shows the trajectory of median BG levels during 48 hours and the difference between the curves was found to be statistically significant $(p=<0.001)$. All median BG levels at specific time points in Group 1 were lower than those of Group 2, but statistical significance was present at $6^{\text {th }}[163(103-247)$ vs. $232(188-294), p=0.009]$, $30^{\text {th }}[176(103-219)$ vs. $258(178-326), p=0.001], 36^{\text {th }}[184$ (139-233) vs. 279 (222-360), $p=<0.001]$, and $48^{\text {th }}[198$ (105-223) vs. 277 (205-316), $p=<0.001]$ hours. Starting insulin dose (U/kg/day) and median glucose levels after starting subcutaneous insulin was found to be mildly correlated $(r=-0.489, p=0.001)$ (Figure 1).

Rates of BG levels $<50 \mathrm{mg} / \mathrm{dL}$ and $<70 \mathrm{mg} / \mathrm{dL}$ were compared between the groups to evaluate the frequency of hypoglycemia, while the frequency of BG levels $>200$ $\mathrm{mg} / \mathrm{dL}$ was evaluated in order to assess hyperglycemia (Table 3). Only two patients in Group 1 had experienced

Table 1. Baseline characteristics of the study group Total group $(\mathrm{n}=76)$

\begin{tabular}{ll}
\hline Age (years) & $10.0(6.0-12.0)$ \\
Male & $44(57.9 \%)$ \\
Pubertal patients & $36(47.4 \%)$ \\
Blood glucose on admission (mg/dL) & $466(383-574)$ \\
pH & $7.17(7.05-7.24)$ \\
Bicarbonate (mmol/L) & $8.85(6.0-12.6)$ \\
HbA1c (\%) & $12.5(10.8-13.8)$ \\
Dose of intravenous insulin (U/h) & $0.1(0.1-0.1)$ \\
Dose of subcutaneous insulin (U/kg/day) & $1.00(0.93-1.44)$ \\
Blood glucose before start of regular & $158(123-198)$ \\
insulin (mg/dL) & \\
\hline
\end{tabular}


BG levels $<50 \mathrm{mg} / \mathrm{dL}$ and those episodes were treated with oral glucose solutions. Frequency of BG levels $<50$ $\mathrm{mg} / \mathrm{dL},<70 \mathrm{mg} / \mathrm{dL}$, and $<100 \mathrm{mg} / \mathrm{dL}$ were similar in the two groups, while the percentage of BG levels $>200 \mathrm{mg} /$ $\mathrm{dL}$ were significantly lower in Group $1(\mathrm{p}=<0.001)$. The number of BG measurements in the target range (100-200 $\mathrm{mg} / \mathrm{dL}$ ) were significantly higher in Group 1 than in Group $2(p=0.001)$.

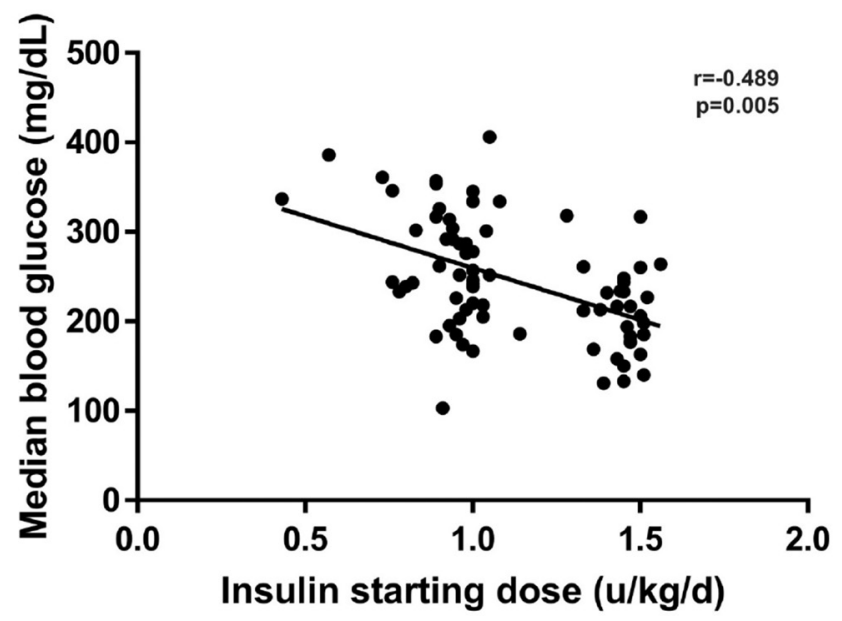

Figure 1. Distribution of the starting subcutaneous insulin doses and its correlation with median blood glucose levels during the first 48 hours of treatment
The minimum and maximum BG levels during 48 hours were significantly lower in Group 1 than in Group $2(p=0.004$ and $\mathrm{p}=0.001$ ) (Table 4). Table 4 presents additional glycemic variability indices of the two groups including $B G$ rate of change, difference between minimum and maximum BG, $\mathrm{SD}$ and $\mathrm{CV}$ of BG.

During follow-up, subcutaneous insulin doses needed to be increased in order to avoid hyperglycemia. As a result, insulin doses (units/kg/d) administered on the second day in both Group 1 [1.63 (1.47-1.77) and Group $2[1.07$

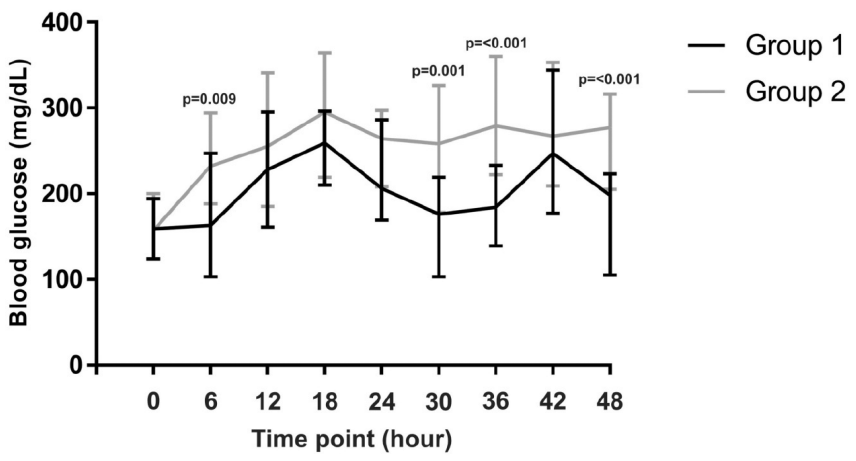

Figure 2. Median, $25^{\text {th }}$, and $75^{\text {th }}$ percentile values of the two groups at baseline and at specific time points during the first two days of subcutaneous insulin treatment. The $p$-values are given where statistically significant differences were present between the two groups

Table 3. The characteristics of blood glucose fluctuations in patients with high-dose and conventional-dose subcutaneous regular insulin after resolution of diabetic ketoacidosis

\begin{tabular}{|c|c|c|c|}
\hline & Group $1(n=28)$ & Group $2(n=48)$ & $\mathrm{p}$ \\
\hline Number of episodes $<50 \mathrm{mg} / \mathrm{dL}$ & $0(0-0)$ & $0(0-0)$ & 0.062 \\
\hline Percentage of episodes $<50 \mathrm{mg} / \mathrm{dL}$ & $0(0-0)$ & $0(0-0)$ & 0.062 \\
\hline Number of patients who experienced episodes $<50 \mathrm{mg} / \mathrm{dL}$ & $2(7.1 \%)$ & $0(0-0)$ & 0.133 \\
\hline Number of episodes $<70 \mathrm{mg} / \mathrm{dL}$ & $0(0-0)$ & $0(0-0)$ & 0.204 \\
\hline Percentage of episodes $<70 \mathrm{mg} / \mathrm{dL}$ & $0(0-0)$ & $0(0-0)$ & 0.234 \\
\hline Number of patients who experienced episodes $<70 \mathrm{mg} / \mathrm{dL}$ & $5(17.9 \%)$ & $4(8.3 \%)$ & 0.276 \\
\hline Percentage of episodes $<100 \mathrm{mg} / \mathrm{dL}$ & $6.25(0-25)$ & $0(0-12.5)$ & 0.021 \\
\hline Percentage of episodes between 100-200 mg/dL & $37.5(25-50)$ & $12.5(3.13-25)$ & 0.001 \\
\hline Percentage of episodes > $200 \mathrm{mg} / \mathrm{dL}$ & $50(25-75)$ & $81.3(62.5-87.5)$ & 0.001 \\
\hline
\end{tabular}

Table 4. Glycemic variability indices among groups

\begin{tabular}{|c|c|c|c|}
\hline & Group $1(n=28)$ & Group $2(n=48)$ & $\mathrm{p}$ \\
\hline BG rate of change $(\mathrm{mg} / \mathrm{dL} / \mathrm{min})$ & $0.5(-0.73-2.13)$ & $2.13(0.89-3.4)$ & 0.001 \\
\hline Minimum BG (mg/dL) & $99(86.3-120)$ & $137(99-192)$ & 0.004 \\
\hline Difference between minimum and maximum BG level (mg/dL) & $222(168-272)$ & $219(169-304)$ & 0.445 \\
\hline Standard deviation & $78.7(55.9-91.5)$ & $75.8(60.8-96.1)$ & 0.504 \\
\hline
\end{tabular}


(1-1.22)] were significantly higher compared to starting doses ( $p<0.001$ for both).

\section{Discussion}

There are different approaches to initiate subcutaneous insulin after resolution of DKA, partly influenced by practice style and health care economics. In some institutions, basal-bolus insulin regimen is initiated immediately after resolution of DKA and the patient is discharged from hospital and further managed as an outpatient. However, many physicians prefer to start with subcutaneous regular insulin prior to discharge and determine the daily insulin requirement for the individual patient. Whichever is preferred, the primary concern is to maintain BG control while avoiding hypoglycemia. Early control of BG with insulin therapy might be associated with improved longterm glycemic control and higher endogenous insulin production $(9,10)$. In practice, total insulin doses of 0.5-0.75 $\mathrm{U} / \mathrm{kg} /$ day are typically chosen at T1DM onset and the dose is then adjusted on a daily basis to achieve the targeted glycemia. However, transition from 1.2-2.4 U/kg/day during treatment for DKA to much lower doses for subcutaneous insulin treatment often results in increase in BG levels, as was the case in the present study in both groups.

It is well-known that the metabolic abnormalities occurring in the diabetic state, in particular hyperglycemia, cause mitochondrial superoxide overproduction, which leads to activation of major pathways involved in the pathogenesis of complications of diabetes (11). Thus, the primary goal of treatment in children and adolescents with T1DM is to maintain near-normoglycemia as early as possible $(12,13)$. In our study, the ratio of BG levels $>200 \mathrm{mg} / \mathrm{dL}$ were significantly lower in Group 1 than in Group $2(p=<0.001)$, a finding from which we may conclude that regular insulin at a dose of 1.4-1.5 U/kg/day prevents hyperglycemia better than the lower doses in the early period. In a previous study, it was reported that BG fluctuations were also associated with oxidative stress with coexistence of high BG levels and suggested that T1DM treatment should aim at reducing glucose fluctuations as well as achieving the overall control (14). In the present study, the difference between minimum and maximum BG, SD and CV of BG were similar in the two groups.

As a matter of fact, the issue that what is more important in the development of vascular damage is controversial in the literature. Peña et al (15) reported that hypoglycemia rather than BG fluctuation was correlated with vascular dysfunction in a pediatric population with T1DM. Moreover, several studies have shown that the most prominent barrier for tight glycemic control is the fear of hypoglycemia $(16,17)$. In our study, there was no statistically significant difference between the groups with regard to hypoglycemia. In Group 1 , only 2 patients had suffered $<50 \mathrm{mg} / \mathrm{dL}$ hypoglycemia (each with 1 BG episode of $<50 \mathrm{mg} / \mathrm{dL}$ ) which was treated with oral glucose solutions. The number and ratio of BG $<70 \mathrm{mg} / \mathrm{dL}$ and $<100 \mathrm{mg} / \mathrm{dL}$ episodes were also similar in the two groups. None of our patients experienced severe hypoglycemia.

Wang et al (5) have recently compared the influence of different subcutaneous insulin infusion doses $(0.6 \pm 0.2 \mathrm{U} /$ $\mathrm{kg} /$ day, $1.0 \pm 0.2 \mathrm{U} / \mathrm{kg} /$ day, and $1.4 \pm 0.2 \mathrm{U} / \mathrm{kg} /$ day) on $\mathrm{BG}$ dynamics of children and adolescents with newly diagnosed T1DM and reported that approximately $90 \%$ of patients tolerated the higher insulin doses $(1.4 \pm 0.2 \mathrm{U} / \mathrm{kg} / \mathrm{day})$ for 2 weeks without showing a significant difference regarding severe hypoglycemia rates. Our results are in line with those results and suggest that higher doses are necessary for better control in the early period. During follow-up, subcutaneous insulin doses needed to be increased in both groups in order to avoid hyperglycemia and the ratio of BG levels in the target range were only $37.5 \%$, even in Group 1. Furthermore, the BG levels of the whole study group were only mildly correlated with initial insulin dose suggesting that higher doses could also be well-tolerated.

Late achievement of glycemic control can also result in increased hospital stay and thus, associated risks of hospitalization. However, due to the retrospective design of our study, we were not able to compare the duration of hospital stays in the two groups. Furthermore, there would be many other confounding factors that could affect hospital stay.

In conclusion, we suggest that an initial dose of 1.4-1.5 U/ $\mathrm{kg} /$ day regular insulin may safely be used after resolution of DKA in children with new-onset T1DM with no increase in risk of hypoglycemia.

\section{Ethics}

Ethics Committee Approval: Clinical and laboratory data were collected and analyzed after Behçet Uz Children's Hospital Ethics Committee's approval, in concordance with the principles of Declaration of Helsinki.

Informed Consent: Not applicable.

Peer-review: Externally and Internally peer-reviewed.

\section{Authorship Contributions}

Concept: Özlem Bağ, Korcan Demir, Design: Özlem Bağ, Korcan Demir, Data Collection and Processing: Özlem Bağ, Selma Tunç, Özlem Nalbantoğlu, Çiğdem Ecevit, Aysel 
Öztürk, Analysis and Interpretation: Korcan Demir, Behzat Özkan, Literature Research: Özlem Bağ, Çiğdem Ecevit, Aysel Öztürk, Korcan Demir, Writing: Özlem Bağ, Korcan Demir.

Financial Disclosure: The authors declared that this study received no financial support.

\section{References}

1. Danne T, Bangstad HJ, Deeb L, Jarosz-Chobot P, Mungaie L, Saboo B, Urakami T, Battelino T, Hanas R; International Society for Pediatric and Adolescent Diabetes. ISPAD Clinical Practice Consensus Guidelines 2014. Insulin treatment in children and adolescents with diabetes. Pediatr Diabetes 2014;15(Suppl 20):115-134.

2. Svoren BM, Jospe N. Type 1 Diabetes Mellitus (Immune Mediated). In: Kliegman RM, Stanton BF, StGeme JW, SchorFN (eds). Nelson Textbook of Pediatrics, 20th ed. Pennsylvania, Elsevier Saunders, 2016;2763-2783.

3. Gualandi-Singorini AM, Giorgi G. Insulin formulations--a review. Eur Rev Med Pharmacol Sci 2001;5:73-83.

4. No authors listed. Effect of intensive therapy on residual beta-cell function in patients with type 1 diabetes in the diabetes control and complications trial. A randomized, controlled trial. The Diabetes Control and Complications Trial Research Group. Ann Intern Med 1998;128:517-523.

5. Wang Y, Gong C, Cao B, Meng X, Wei L, Wu D, Liang X, Li W, Liu M, Gu $Y$, Su C. Influence of initial insulin dosage on blood glucose dynamics of children and adolescents with newly diagnosed type 1 diabetes mellitus. Pediatric Diabetes 2016;18:196-203. Epub 2016 Mar 6

6. Craig ME, Jefferies C, Dabelea D, Balde N, Seth A, Donaghue KC; International Society for Pediatric and Adolescent Diabetes. ISPAD Clinical Practice Consensus Guidelines 2014. Definition, epidemiology, and classification of diabetes in children and adolescents. Pediatric Diabetes 2014;15(Suppl 20):4-17.

7. Williams JR. The Declaration of Helsinki and public health. Bull World Health Organ 2008;86:650-652.
8. Smart CE, Annan F, Bruno LP, Higgins LA, Acerini CL; International Society for Pediatric and Adolescent Diabetes. ISPAD Clinical Practice Consensus Guidelines 2014. Nutritional management in children and adolescents with diabetes. Pediatr Diabetes 2014;15(Suppl 20):135153.

9. Colino E, Álvarez MÁ, Carcavilla A, Alonso M, Ros P, Barrio R. Insulin dose adjustment when changing from multiple daily injections to continuous subcutaneous insulin infusion in the pediatric age group. Acta Diabetol 2010;47(Suppl 1):1-6. Epub 2009 Mar 25

10. Wolfsdorf J, Craig ME, Daneman D, Dunger D, Edge J, Lee W, Rosenbloom A, Sperling M, Hanas R. Diabetic ketoacidosisin children and adolescents with diabetes. Pediatr Diabetes 2009;10(Suppl 12):118-133.

11. Giacco F, Brownlee M. Oxidative stress and diabetic complications. Circ Res 2010;107:1058-1070.

12. International Society for Pediatric and Adolescent Diabetes. 2011 global IDF/ISPAD guideline for diabetes in childhood and adolescence [Internet]. ISPAD.org. 2011 [cited 2012 Jan 9]. 1-132.Available from: https://www.ispad.org/sites/default/files/idfispad_diabetes_in_ childhood_and_adolescence_guidelines_2011.pdf.].

13. Malik FS, Taplin CE. Insulin therapy in children and adolescents with type 1 diabetes. Paediatr Drugs 2014;16:141-150

14. Meng X, Gong C, Cao B, Peng X, Wu D, Gu Y, Wei L, Liang X, Liu M, $\mathrm{Li}$ W, Su C. Glucose fluctuations in association with oxidative stress among children with T1DM: comparison of different phases. J Clin Endocrinol Metab 2015;100:1828-1836. Epub 2015 Feb 25

15. Peña AS, Couper JJ, Harrington J, Gent R, Fairchild J, Tham E, Baghurst P. Hypoglycemia, but not glucose variability, relates to vascular function in children with type 1 diabetes. Diabetes Technol Ther 2012;14:457462. Epub 2012 Feb 7

16. Gonder-Frederick L, Nyer M, Shepard JA, Vajda K, Clarke W. Assessing fear of hypoglycemia in children with type 1 diabetesand their parents. Diabetes Manag (Lond) 2011;1:627-639.

17. Tridgell DM, Tridgell AH, Hirsch IB. Inpatient management of adults and children with type 1 diabetes. Endocrinol Metab Clin North Am 2010;39:595-608. 